\title{
Predictive factors for hepatocellular carcinoma recurrence after curative treatments
}

\author{
Giovanni Marasco', Federico Ravaioli', Amanda Vestito', Benedetta Rossini', Elton Dajti', Luigi \\ Colecchia ${ }^{1}$, Kamela Gjini ${ }^{3}$, Matteo Renzulli ${ }^{2}$, Rita Golfieri ${ }^{2}$, Davide Festi ${ }^{1}$, Antonio Colecchia ${ }^{3}$ \\ 'Department of Medical and Surgical Sciences (DIMEC), University of Bologna, Bologna 40138, Italy. \\ ${ }^{2}$ Radiology Unit, Sant'Orsola Malpighi Hospital, Bologna 40138, Italy. \\ ${ }^{3} U$ nit of Gastroenterology, Borgo Trento University Hospital of Verona, Verona 37126, Italy.
}

Correspondence to: Dr. Antonio Colecchia, Unit of Gastroenterology, Borgo Trento University Hospital, Verona 37126, Italy. E-mail: antonio.colecchia@aovr.veneto.it

\begin{abstract}
How to cite this article: Marasco G, Ravaioli F, Vestito A, Rossini B, Dajti E, Colecchia L, Gjini K, Renzulli M, Golfieri R, Festi D, Colecchia A. Predictive factors for hepatocellular carcinoma recurrence after curative treatments. Hepatoma Res 2020;6:33. http://dx.doi.org/10.20517/2394-5079.2020.01
\end{abstract}

Received: 14 Jan 2020 First Decision: 16 Mar 2020 Revised: 13 May 2020 Accepted: 15 May 2020 Published: 18 Jun 2020

Science Editor: Stefano Brillanti Copy Editor: Jing-Wen Zhang Production Editor: Tian Zhang

\begin{abstract}
Hepatocellular carcinoma (HCC) is the fifth most common neoplasm worldwide. Recurrence of HCC after resection or loco-regional therapies represents an important clinical issue as it affects up to $70 \%$ of patients. This can be divided into early or late, if it occurs within or after 24 months after treatment, respectively. While the predictive factors for early recurrence are mainly related to tumour biology (local invasion and intrahepatic metastases), late recurrences are mainly related to de novo tumour formation. Thus, it is important to recognize these factors prior to any treatment in each patient, in order to optimize the treatment strategy and follow-up after treatment. The aim of this review is to summarize the current evidence available regarding predictive factors for the recurrence of HCC, according to the different therapeutic strategies available. In particular, we will discuss the role of new ultrasound-based techniques and biological features, such as tumor-related and circulating biomarkers, in predicting HCC recurrence. Recent advances in imaging-related parameters in computed-tomography scans and magnetic resonance imaging will also be discussed.
\end{abstract}

Keywords: Liver resection, trans-arterial chemoembolization, radiofrequency ablation, liver stiffness measurement, indocyanine green retention test

\section{INTRODUCTION}

Hepatocellular carcinoma (HCC) is the fifth most common tumor and one of the leading causes of cancer mortality worldwide ${ }^{[1,2]}$. To date, the numbers of HCC has not dropped, despite the introduction of new direct antiviral agents for hepatitis virus $\mathrm{C}(\mathrm{HCV})$ eradication ${ }^{[3]}$ to lower the risk of developing $\mathrm{HCC}$ in these 
patients ${ }^{[3]}$. HCC remains a widespread tumor due to the persistence of a high prevalence of hepatitis B virus (HBV) infection in African and Asian countries, and from the increasing incidence of non-alcoholic fatty liver disease, alcoholic and non-alcoholic steatohepatitis (ASH/NASH) patients in Western countries.

There are different therapeutic strategies to manage HCC according to both the underlying extent of liver disease and tumor-related factors, as stated by the different guidelines available ${ }^{[2,4-6]}$. The recommended treatment of choice in these guidelines is mainly an adaptation from the BCLC classification ${ }^{[2,7]}$. Patients with HCC are classified into five stages by tumor related factors (size, number, vascular invasion, N1, M1), liver function (bilirubin, portal hypertension, liver function preservation) and health status (ECOG) ${ }^{[2]}$. These guidelines were developed to provide the best treatment to maximize overall survival (OS) according to tumor characteristics listed above. Liver resection (LR) is recommended mainly for single HCCs of any size and in particular, for size $>2 \mathrm{~cm}$, with preserved hepatic function and sufficient residual liver volume. In patients with BCLC 0 and $\mathrm{A}$, or in single tumors 2 to $3 \mathrm{~cm}$ in size not suitable for surgery, the treatment of choice is thermal ablation with radiofrequency (RFA) as an alternative to surgical resection. In patients with BCLC B, trans-arterial chemoembolization (TACE) is recommended ${ }^{[2]}$. Even though treatment choice is tailored for individual patients, HCC recurrence remains the most important concern and can occur irregardless of treatment ${ }^{[8]}$.

In fact, in curative treatments such as liver resection, HCC recurrence developes in up to $70 \%$ of patients at 5 years after hepatic resection, both within (early recurrence) or after 24 months (late recurrence) ${ }^{[1,2,9]}$. Several authors ${ }^{[10-13]}$ have explored the differences between early and late recurrence and investigated the risk factors for each. Predictive factors for early recurrence are well-known ${ }^{[14]}$. On the other hand, the prediction of late recurrences is limited by poor data; it can also be considered a 'de novo' tumour and thus, has been associated mainly with the degree of fibrosis and extent of portal hypertension $(\mathrm{PH})^{[15-17]}$.

The aim of this review is to summarize the most recent advances in the role of predictive factors for HCC recurrence in patients undergoing curative HCC treatment beyond liver transplantation such as LR, RFA and TACE. Furthermore, when possible, biomarkers and imaging predictors are also differentiated.

\section{LIVER RESECTION}

LR is the standard of care of patients with solitary tumors and preserved liver function ${ }^{[4,5]}$. The major complication after LR is HCC recurrence which reaches an incidence of more than $70 \%$ at 5 years ${ }^{[14]}$. As stated, HCC recurrence can be classified as early or late ${ }^{[1,118]}$. Early recurrences have well-established predictive factors which are mainly related to tumor biology (i.e., tumor size, tumor number, presence of microsatellites and vascular invasion) and the treatment modality used ${ }^{[14]}$. In particular, vascular invasion (both macroscopic and microscopic) is one of the most reliable predictors of recurrence and survival and strictly associated with histological differentiation and tumor size ${ }^{[14]}$. On the other hand, the development of late recurrences is widely considered a de novo HCC affected by the underlying liver status ${ }^{[19,20]}$. Thus, the presence and degree of $\mathrm{PH}$ could play an important role in predicting late recurrences. Indeed, the extent of $\mathrm{PH}$ is directly correlated with the risk of developing complications ${ }^{[21-24]}$, including $\mathrm{HCC}^{[25]}$. Recently, several studies have highlighted the role of non-invasive tests such as liver (LSM) and spleen stiffness measurements (SSM) as predictors of late recurrence of $\mathrm{HCC}^{[16,17,26]}$. The predictive factors for early and late HCC recurrence after LR are summarized in Table 1.

\section{Early HCC recurrence}

Tumor-related factors

A clear correlation has already been highlighted between tumor size, number and HCC recurrence ${ }^{[27]}$. These factors remain the best pre-operative prognostic factors such that both the American and European Association for the Study of the Liver endorsed these criteria in their staging systems ${ }^{[2,4]}$. Indeed, HCC 
Table 1. Predictive factors for early and late HCC recurrence after liver resection

\begin{tabular}{|c|c|c|}
\hline & Early recurrence & Late recurrence \\
\hline \multicolumn{3}{|l|}{ Tumor related factors } \\
\hline Tumor size & {$[27-29]$} & {$[27-29]$} \\
\hline Tumor grade & {$[29-32]$} & [29] \\
\hline Macrovascular invasion & {$[19,33-35]$} & [19] \\
\hline Microvascular invasion & {$[19,36-39]$} & {$[19,37]$} \\
\hline Satellite nodules & {$[40]$} & - \\
\hline Tumor-free margins & [41-43] & {$[41,43]$} \\
\hline \multicolumn{3}{|l|}{ Biomarkers } \\
\hline AFP & {$[32,35,44-46]$} & {$[27,28]$} \\
\hline Immunomarkers & {$[47-54]$} & - \\
\hline ERASL-pre score & [55] & - \\
\hline REACH score & {$[56]$} & - \\
\hline SVR & [57] & {$[58-60]$} \\
\hline HBV replication & {$[61]$} & {$[15,61]$} \\
\hline Alcohol intake & & {$[62,63]$} \\
\hline \multicolumn{3}{|l|}{ Others } \\
\hline MicroRNAs & {$[64,65]$} & - \\
\hline Imaging factors & {$[66-75]$} & \\
\hline IGC15 & - & [16] \\
\hline Sarcopenia & {$[76]$} & - \\
\hline \multicolumn{3}{|l|}{ NITs } \\
\hline LSM & - & {$[16,26,77]$} \\
\hline SSM & - & [17] \\
\hline FIB-4 & - & {$[78]$} \\
\hline$A L B I>2$ & {$[55,79-82]$} & {$[78,83,84]$} \\
\hline Platelet/spleen length ratio & - & {$[17]$} \\
\hline
\end{tabular}

HCC: hepatocellular carcinoma; AFP: alpha-fetoprotein; ERASL: early recurrence after surgery for liver tumor; REACH-B: estimates risk of HCC in patients with chronic hepatitis B; SVR: sustained virological response; HBV: hepatitis B virus; IGC15: indocyanine green retention rate at 15 min; NITs: non-invasive tests; LSM: liver stiffness measurement; SSM: spleen stiffness measurement; FIB4: fibrosis-4 index; ALBI: albumin-bilirubin grade

nodules $\geq 5 \mathrm{~cm}$ are associated with an increased recurrence rate due to the higher risk of portal vein ${ }^{[28]}$ and micro-vascular invasion (MVI) ${ }^{[36]}$. Besides, vascular invasion represents another good predictor of tumor recurrence ${ }^{[19,27]}$. It could be defined as macroscopic, when it is visible on imaging or even on gross examination, and microscopic, when seen only on histological examination. The presence of macrovascular invasion is able to reduce the time to recurrence by 4 -fold ${ }^{[19]}$. Moreover, extension of portal vein thrombosis is directly related to poor prognosis ${ }^{[3,34]}$.

With regard to MVI, it is usually defined as the presence of tumour emboli within the central hepatic vein, the portal vein, or the large capsular vessels ${ }^{[12]}$. Unfortunately, this evaluation is subject to great variability which affects the true incidence of this condition ${ }^{[37]}$. The presence of MVI is related to an increased risk of HCC recurrence ${ }^{[19,38,39]}$. The main limitation of MVI assessment depends on its timing since it is often obtained on resected specimens. MVI can be accurately assessed only on resected specimens, which constitutes a strong limitation to such assessment ${ }^{[29,30,35]}$. Tumor grade (grade $3 / 3$ ) and tumor size have also been associated with early HCC recurrence and are strictly related to MVI ${ }^{[29-32]}$.

Several authors have tried to evaluate the usefulness of other pre-operative parameters beyond tumor grade in predicting MVI, such as increased alpha-fetoprotein (AFP), L3-AFP and prothrombin induced by vit K absence-II (PIVKA-II) ${ }^{[30,31,35]}$. Recently, a low concentration of the autophagy-related marker LC $3^{[85]}$ on HCC and adjacent non-tumor tissues has also been found to be a significant predictor of both early and late HCC recurrence. A further recent study ${ }^{[47]}$ evaluated the role of immunohistochemical markers in a large cohort of resected HCC, concluding that 14 factors showed a prognostic role for predicting recurrence, including 
6 clinico-pathological characteristics (clinical stage, differentiation level, capsular invasion, tumor number, tumor diameter, and AFP level) and 8 immunomarkers (CD34, CDKN1A, E-cadherin, HRas, PCNA, p53, TGF- $\beta$ and VEGF). Other authors ${ }^{[8]}$ evaluated the Epstein-Barr virus-induced gene 3 (EBI3) which encodes a secretory glycoprotein which was previously found to be upregulated in different tumors; they found that EBI3 was a predictor for tumor recurrence. Among the myriad of other tumoral-tissue related markers, a prognostic role was also reported for the Peroxiredoxin $1(\mathrm{PRDX} 1)^{[87]}$; the divalent metal-ion transporter-1 $(\mathrm{DMT} 1)^{[88]}$; the cell cycle factor NIMA-related kinase $2\left(\mathrm{NEK}_{2}\right)^{[89]}$; among the non-coding tumoral RNAs, the miR-210 and miR-550a-1 were associated with a high risk of recurrence ${ }^{[64]}$, similar to miR-483-3p ${ }^{[65]}$; low c-Myc protein expression ${ }^{[90]}$; low MHC class I chain-related gene A $(M I C A)^{[91]}$; the long noncoding RNA (lncRNA) expression signature ${ }^{[92]}$; and the NUF2 ${ }^{[93]}$. However, all these tumoral-tissue related markers have not found clinical application yet.

\section{Circulating biomarkers}

Several circulating markers have been identified to be able to predict early HCC recurrence. Certainly, AFP is used not only for diagnosing HCC but also plays a key role in predicting recurrence ${ }^{[44-46]}$ with a cut-off that has recently been lowered from $200 \mathrm{ng} / \mathrm{mL}$ to $100 \mathrm{ng} / \mathrm{mL}^{[46]}$. Since the liver is the organ that synthesizes lipoprotein (a) [Lp (a)], reduced levels of this lipoprotein could be a sign of liver dysfunction. Thus, as Lp (a) mirrors hepatic function and the degree of underlying disease, it has recently been found ${ }^{[94]}$ in a cohort of HCC patients that low Lp (a) levels $(\leq 20 \mathrm{mg} / \mathrm{dL})$ significantly correlated with low time to recurrence $(P=0.009)$ and low OS $(P=0.007)$. Among other circulating markers or composite scores, the albuminbilirubin (ALBI) score has been validated as a predictor of survival in $\mathrm{HCC}^{[79]}$. Recently, an Asiatic study ${ }^{[80]}$ evaluated the role of ALBI in predicting early recurrence. It was found that an ALBI grade $\geq 2$ $(P=0.003)$ in addition to HBV surface antigen (HBsAg)-positive status $(P<0.001)$, tumor size $\geq 3.5 \mathrm{~cm}$ $(P \leq 0.001)$, lympho-vascular invasion $(P=0.001)$, and the presence of satellite lesions $(P=0.009)$ were the only predictors of early HCC recurrence on multivariate analysis. The same results on ALBI were recently reported by other authors ${ }^{[55,81,82]}$, among whom Chan et al ${ }^{[55]}$ developed the ERASL-pre score, which included male gender, large tumor size, multinodular tumors, high ALBI grade and high serum AFP. More recently, an elevated fibrinogen/albumin ratio was found ${ }^{[95]}$ to be significantly correlated with shorter survival and an increase risk of HCC recurrence. On the same line, the ratio between high-sensitivity C-reactive protein (hsCRP) and albumin was associated with a 1.19-fold increase in the risk of HCC recurrence ${ }^{[96]}$. In an additional study on hsCRP, it was found to be associated with lymphocyte ratio (HCLR) and positively correlated with large tumor size, TNM stage, MVI, and HCC recurrence ${ }^{[48]}$. A further composite score is represented by $\mathrm{REACH}^{[56]}$ which includes $\mathrm{NxS}$ factor, MVI, differentiation, serum albumin, platelet count and indocyanine green retention rate at $15 \mathrm{~min}$ and was able to predict the risk of HCC recurrence.

Other simple factors that are able to predict early recurrence of HCC that should be taken into account are the lymphocyte and neutrophil levels computed into the $\mathrm{NLR}^{[49]}$, which mirrors a pro-tumor inflammatory environment and the activity of host immunity. In fact, these authors found that patients with pre-operative NLR $<2.5$ were at lower risk of recurrence. Thus, others have tried to refine the predictive value of these scores by building a composite score with ALBI and platelet to-lymphocyte ratio ${ }^{[97]}$, which was able to predict the outcome after liver resection, including HCC recurrence. Platelet to-lymphocyte ratio was further associated with NLR with good results ${ }^{[50]}$. Finally, other immune-biomarkers that have promising results are the lymphocyte-to-monocyte ratio ${ }^{[51]}$, gamma-glutamyl transpeptidase to lymphocyte count ratio ${ }^{[52]}$ and systemic inflammation score ${ }^{[53]}$. A Chinese group ${ }^{[54]}$ recently demonstrated that IgG4/IgG ratio is an independent indicator of tumor recurrence and a high ratio is associated with a shorter time to recurrence.

Circulating microparticles are novel biomarkers with a potential prognostic role in patients with cancer. Their role in HCC has been investigated by Abbate et al. ${ }^{[98]}$ and it was found that the number of circulating HepPar1+ microparticles before resection was higher in patients with early recurrence compared to those 
without $(P=0.02)$. With regard to other cancer biomarkers, platelet derived growth factor-BB has been claimed to be one of the key cytokines in malignant transformation of different cells and recently ${ }^{[99]}$, diminished perioperative platelet derived growth factor-BB has been linked to HCC recurrence. Another potential biomarker concerns serum proteome alterations ${ }^{[100]}$ : PGK1, which is directly involved with carcinogenesis and the intracellular inflammation cascade, was found to be increased in patients with early tumor recurrence. Recently, a glycan-based immunoassay targeting Wisteria floribunda agglutinin-positive human Mac-2 binding protein ( $\mathrm{WFA}^{+}-\mathrm{M} 2 \mathrm{BP}$ ) was evaluated as a noninvasive biomarker of liver fibrosis and predictor of HCC and HCC recurrence, as it was associated with pro-carcinogenic activity in patients with chronic liver disease ${ }^{[101]}$. In a further study, it was associated with both early $(\mathrm{HR}=1.667)$ and late recurrence $(\mathrm{HR}=1.416)$ with multivariate analysis ${ }^{[102]}$.

In conclusion, some circulating biomarkers have gradually been endorsed in clinical practice in several centers for their simplicity and real-time application based on standard liver tests, and are able to give reliable prognostic information on these patients.

\section{Imaging predictive factors}

Pre-operative imaging signatures have been proposed in the last decade for predicting HCC recurrence before resection. With regard to computed-tomography (CT) scan prediction, beyond the classic HCC features associated with HCC recurrence, a HCC texture based study found good correlation with histological grade and thus, the risk of disease recurrence ${ }^{[6]]}$.

As for magnetic resonance imaging (MRI), correlation between the preoperative diffusion-weighted imaging and early recurrence has been found ${ }^{[67,68]}$, specifically ${ }^{[67]}$ with minimal apparent diffusion coefficient values. Several studies reported that imaging findings based on peri-tumoral tissue enhancement and hypointensity in the hepatobiliary phase were useful for predicting MVI and early recurrence in $\mathrm{HCC}^{[68-70]}$.

A Korean study carried out in $2017^{[70]}$, which is one of the largest among those stated above, included 197 patients and using gadoxetic acid-enhanced MRI for predicting MVI, highlighted that the combination of at least two of the following - arterial peri-tumoral enhancement, non-smooth tumor margin, and peri-tumoral hypointensity on hepatobiliary phase - was able to predict MVI with $>90 \%$ specificity and associated with early recurrence after a single HCC nodule resection. These results have been further confirmed by other groups worldwide ${ }^{[68,69]}$. To enhance the predictive accuracy of these findings, a recent study ${ }^{[71]}$ used Radiomics on CT-scans for this purpose. Radiomics is a new method for medical image analysis ${ }^{[72]}$, defined as the highthroughput extraction of quantitative metric features that result in the conversion of images into mineable data. These authors ${ }^{[71]}$ found that peri-tumoral radiomics was better in predicting HCC early recurrence than tumoral radiomics ${ }^{[73]}$. Other authors using radiomics on pre-operative CT-scans found a good correlation with MVI (AUC 0.80) ${ }^{[74]}$. Beyond texture, using 3D MRI was also possible to evaluate tissue stiffness; a multicenter study ${ }^{[75]}$ recently found that HCCs with subsequent recurrence had higher tumor stiffness.

Finally, an additional prognostic role has also been investigated for fluoro-deoxyglucose (FDG)-positron emission tomoscintigraphy (PET). Indeed, a recent study ${ }^{[103]}$ with FDG-PET before surgery concluded that a larger tumor size and serum AFP were correlated with higher SUV max ( $\geq 4.9)$, which was able to distinguish between patients with or without HCC recurrence after resection.

Beyond the standard evaluation of HCC (tumor number, size, location, vascular invasion) however, the above evaluation methods remain as research and are only applied in highly specialized centers.

\section{Resection-related factors}

Strong evidence is available on the role of tumor-free margins in $\mathrm{HCC}^{[104]}$. Most previous studies have stated that tumor margins should be at least $1 \mathrm{~cm}^{[42,43]}$. A randomized controlled trial showed however, that in order to improve survival margins should be at least $2 \mathrm{~cm}^{[104]}$. 
On the other hand, the extent of resection is another key factor to take into account when predicting tumor recurrence. If anatomical resection (whole hepatic segment) allows reduction of risk for intrahepatic metastasis due to microsatellite nodules and segmental neoplastic thrombi, most surgeons would prefer nonanatomical resections instead in order to reduce the risk of post-hepatectomy liver failure ${ }^{[40]}$. Most studies on this topic are affected by much heterogeneity amongst the patients enrolled, since non-anatomical resections are performed mainly in patients with small HCC nodules and with a higher degree of liver dysfunction. A large series has demonstrated that non-anatomical resection is equally safe in terms of recurrence for HCC nodules less than $2 \mathrm{~cm}^{[105]}$. On the other hand, for larger tumors, anatomical resection is equally able to guarantee a lower rate of early HCC recurrence ${ }^{[8]}$.

\section{Late $\mathrm{HCC}$ recurrence}

Late HCC recurrence is currently not considered a true recurrence of the primary HCC since it seems to be a "de novo" tumor and thus, dependent on the degree of underlying liver cirrhosis ${ }^{[106]}$. Most studies on this topic highlight predictive factors for late recurrence including the severity of liver cirrhosis, presence of active hepatitis and the degree of $\mathrm{PH}^{[1,16,17,26,57,61,77,107]}$. Indeed, the sole presence of liver cirrhosis itself leads to a doubling of risk for late recurrences ${ }^{[11]}$. In the specific setting of HBV, Ishak activity $>6$, an indocyanine green clearance (ICG-15) $>10 \%$ and $\mathrm{HBsAg}>250 \mathrm{IU} / \mathrm{mL}$ were found to be predictors of late HCC recurrence ${ }^{[15,61]}$. With regard to HCV etiology, a recent study ${ }^{[58]}$ demonstrated that HCV-eradication was able to reduce the recurrence of HCC, independent of HCC treatment and the HCV-treatment regimen administered. Further confirmation of the importance of viral eradication came from a recent North American study ${ }^{[59]}$ on new direct antiviral agents and regimens, which demonstrated that the risk of HCC recurrence was not increased by this treatment, as previously postulated ${ }^{[60]}$. Even continuous alcohol intake in patients with Alcohol-related Liver Disease seems to be a HCC risk factor for both the occurrence of primary HCC and late recurrences, since the development of HCC depends both on direct (genotoxic) and indirect factors (cirrhosis development) ${ }^{[62,108]}$. Indeed, a recent study by Kudo et al. ${ }^{[63]}$ found that preoperative excessive alcohol intake was related to decreased disease-free survival rate of HCC recurrence after surgery. Similarly, the presence of obesity at the time of LR has been reported as a risk factor for HCC recurrence ${ }^{[109]}$.

Going back to liver cirrhosis, also in this setting there is an increasing need for non-invasive tests to stratify late HCC recurrences. One of the most frequently used and non-invasive test is the ALBI grade ${ }^{[83]}$, which is an objective and discriminatory method for assessing liver function in HCC, and is gradually replacing the Child-Pugh score. The ALBI has also been found to be a predictor of late HCC recurrence after resection ALBI grades 2 and $3(P<0.001)^{[84]}$. Recently, a composite score ${ }^{[110]}$ for predicting both early and late HCC recurrences in HBV has been developed and validated; this DFT score includes liver function through the use of FIB-4, which is a surrogate marker of liver fibrosis, tumor burden and grade of differentiation. A combination of ALBI and FIB-4 has also been proposed with good accuracy in predicting HCC recurrence ${ }^{[78]}$.

In line with these efforts, Jung et al. ${ }^{[26]}$ found that patients with LSM values $>13.4$ kilopascal $(\mathrm{kPa})$ were at increased risk for late HCC recurrence with a HR of 1.9. Another research group followed up patients with HCC after treatment and found that a decrease in $\mathrm{LSM}<8 \mathrm{kPa}$ suggested a reduced risk of late recurrence ${ }^{[77]}$. In a subsequent study by Jung et al. ${ }^{[16]}$, the LSM value, together with activity grade II-III, the presence of multiple tumours, and ICG R15 achieved good accuracy in predicting late HCC recurrence. Another noninvasive test capable of mirroring the degree of $\mathrm{PH}$ is the evaluation of $\mathrm{SSM}^{[23,24,111,112]}$, which has been demonstrated to be associated with post-hepatectomy liver failure too ${ }^{[113]}$. We recently demonstrated ${ }^{[17]}$ in a cohort of compensated advanced chronic liver disease patients undergoing LR for primary HCC, that univariate analyses of late HCC recurrences were associated with esophageal varices, spleen length, platelet/ spleen length ratio, LSM and SSM. Multivariate analyses however, showed that SSM was the only predictor of late recurrence $(\mathrm{HR}=1.046)$. Thus, it is possible to conclude that NITs focused on the evaluation of the 
Table 2. Predictive factors for HCC recurrence stratified by ethanol percutaneous injection, radiofrequency ablation and trans-arterial chemoembolization

\begin{tabular}{lccc}
\hline & Ethanol percutaneous injection & Radiofrequency ablation & Trans-arterial chemoembolization \\
\hline Tumor related factors & {$[114,116,118]$} & {$[130,131]$} & {$[132]$} \\
Tumor size & {$[121]$} & {$[130]$} & {$[133]$} \\
Tumor grade & {$[120]$} & & {$[132]$} \\
Macrovascular invasion & {$[121,122]$} & & {$[135-138]$} \\
Satellite nodules & & {$[131,134]$} & {$[140-142]$} \\
Intra-tumoral septa & & {$[139]$} & {$[143,144]$} \\
Tumor-free margins & {$[116,121]$} & {$[130]$} & {$[145,146]$} \\
Angiogenic factor & & & {$[149-152]$} \\
Biomarkers & & {$[147,148]$} & {$[153-163]$} \\
AFP & & & {$[76,164]$} \\
Immunomarkers & & \\
ALBI & & & \\
HBV replication & & \\
Genetic factors & & \\
MicroRNAs & & \\
Imaging factors & & \\
Sarcopenia & & \\
\hline
\end{tabular}

AFP: alpha-fetoprotein; ALBI: albumin-bilirubin grade; HBV: hepatitis B virus; HCC: hepatocellular carcinoma

degree of liver fibrosis and function and thus, also of $\mathrm{PH}$, are capable of predicting the future development of HCC nodules in patients who have undergone LR for primary HCC.

\section{ETHANOL PERCUTANEOUS INJECTION}

Patients with early stage HCC, who are not suitable for resection or transplantation, are ideal candidates for percutaneous ablation. Guidelines for locoregional therapy include patients with a single HCC nodule $\leq 5 \mathrm{~cm}$ or up to 3 nodules $\leq 3 \mathrm{~cm}$, even if minor discrepancies exist between different investigators and studies ${ }^{[114]}$. Percutaneous ethanol injection (PEI) is a percutaneous, ultrasound-guided ablative procedure involving the injection of $95 \%$ absolute alcohol which induces coagulative necrosis of the lesion due to protein denaturation, cellular dehydration and chemical occlusion of small tumor vessels ${ }^{[1]}$. PEI was first described in the early $1980 \mathrm{~s}^{[115]}$ and had long been the standard in ablation. Indeed, this technique is the most studied type of percutaneous ablation ${ }^{[116]}$. PEI is also an inexpensive and well-tolerated procedure with few adverse effects, and has been considered the standard against which any new ablation therapy should be compared to ${ }^{[117]}$. Predictors of HCC recurrence after PEI are summarized in Table 2.

The most important predictor of treatment efficacy and HCC recurrence in this setting is tumor size. Indeed, tumors less than $2 \mathrm{~cm}$ in diameter have more than $90 \%$ tumor necrosis rate. As the tumor size increases however, the necrosis rate decreases and for tumors 3 to $5 \mathrm{~cm}$ in size, this rate is only $50 \%{ }^{[114]}$. Notably, the major limitation of PEI is the high local recurrence rate, particularly for lesions larger than $3 \mathrm{~cm}^{[118]}$. Other potential factors affecting tumor recurrence are the total number of treated lesions, satellite nodules, the presence of a halo and an intra-tumoral heterogeneous echo pattern or intra-tumoral septa and AFP levels $>20 \mathrm{mg} / \mathrm{dL}^{[119-121]}$. When the size of the nodule increases, intra-tumoral septation increases, which is mainly composed of collagen and lipid matrix ${ }^{[122]}$. A possible explanation is that ethanol diffusion is blocked either by intra-tumoral fibrotic septa and/or the tumor capsule, limiting its curative effect in lesions larger than $2 \mathrm{~cm}^{[122,123]}$. In addition, the OS is modified by the size of the tumor. Patients with Child-Pugh class A function and a solitary HCC smaller than $2 \mathrm{~cm}$ have 3 - and 5-year OS rates of $70 \%$ to $80 \%$ and $\geq 50 \%$, respectively. For HCCs 2 to $3 \mathrm{~cm}$ in diameter, the 3 -year OS rate ranges from $47 \%$ to $64 \%^{[124,125]}$. To overcome the limits of conventional PEI in patients with tumors larger than $2 \mathrm{~cm}$ that cannot be treated with other procedures, a retractable multipronged injection needle was developed ${ }^{[126]}$. Chemical ablation with $15 \%$ 
acetic acid with the use of a multiple-tine infusion device resulted in larger diameters of contiguous tumor coagulation and enabled greater volumes of infusion than the standard technique ${ }^{[126]}$. However, as this is associated with higher recurrence rates and inferior OS compared to hyper-thermic ablation ${ }^{[127,128]}$, it only plays a secondary role in HCC treatment today, having widely been replaced by more modern techniques such as RFA ${ }^{[129]}$, mainly because it has to be performed repetitively compared to RFA. Furthermore, it is difficult to obtain complete necrosis for tumors larger than $3 \mathrm{~cm}^{[114]}$.

\section{RADIOFREQUENCY ABLATION}

RFA is a non-surgical, curative treatment for $\mathrm{HCC}^{[165]}$ which is designed to destroy the tumor by heating ${ }^{[166]}$. The heat (above $60^{\circ} \mathrm{C}$ ) generated by alternating current passing down from the tip of an electrode into the surrounding tissues induces changes in ionic agitation and drives extracellular and intracellular water out of tissues, resulting in their destruction by coagulative necrosis ${ }^{[16,167]}$. Heat is administered by probes that are inserted through the skin (percutaneously), laparoscopically or with open surgery ${ }^{[168]}$. In cirrhotic patients treated with RFA for HCC, the 5 -year OS reached $74 \%{ }^{[169]}$. Thus, RFA is considered a viable and curative alternative treatment to LR in these patients ${ }^{[170]}$. Based on current guidelines, RFA is performed on single lesions $<5 \mathrm{~cm}$ in diameter or $\leq 3$ lesions $<3 \mathrm{~cm}$ in largest diameter, Child-Pugh class A or B, and ECOG $0^{[2]}$. The high rates of post-procedural recurrence, which might be up to $70 \%$ at 5 years, remain a major challenge for long-term survival ${ }^{[130]}$. Recurrence after RFA for HCC occurs as a result of local tumor progression (LTP) or intrahepatic distant recurrence. LTP occurs along the peripheral margin of the ablative zone when the primary tumor had not been controlled completely after RFA ${ }^{[131]}$. Several risk factors have been associated with local recurrence including tumor size more than $2 \mathrm{~cm}$, poorly differentiated carcinoma, advanced tumor stage, high AFP levels, and an insufficient safety margin ${ }^{[13]}$. An ablative margin of at least $5 \mathrm{~mm}$ is required to avoid the risk of LTP because microsatellite lesions are frequently present and surround the HCC nodule ${ }^{[134]}$. The risk of local recurrence is also closely related to the location of the tumor: HCCs next to the portal vein or major hepatic veins were associated with a higher risk for local recurrence $(\mathrm{HR}=1.70-2.81)$ because the patient's blood flow reduces elevation of the tumor's temperature during $\mathrm{RFA}^{[171]}$. Several studies have reported the ability of AFP levels to predict response to ablation: serum AFP increase have been shown to predict a higher risk of HCC recurrence after ablation treatment ${ }^{[130]}$. The heterogeneity of the studies precludes the formulation of a definite magnitude level, but it is suggested that AFP cut off levels of $>200$ and/or $>400 \mathrm{ng} / \mathrm{mL}$ are associated with poor outcomes ${ }^{[2]}$. In contrast to local recurrence, distant intrahepatic recurrence is observed far from the ablation zone and corresponds usually to de novo hepatocarcinogenesis on cirrhosis or metastatic dissemination ${ }^{[172]}$. Similar to LR, HCC recurrence following RFA occurring early within 2 years of follow-up - is considered the result of an intrahepatic metastatic process from the primary tumor (related to tumor biology), whereas late recurrence after 2 years would result only from de novo carcinogenesis in cirrhosis ${ }^{[170]}$. The Child-Pugh score is associated with distant HCC recurrence; this would suggest that the severity of liver disease is a risk factor not only for HCC occurrence but also for distant HCC recurrence ${ }^{[173]}$. The link between HBV replication (high pre-procedural serum viral load $\geq 2000 \mathrm{UI} / \mathrm{mL}$ ) and the recurrence of HCC after RFA suggests that secondary chemoprevention with nucleos(t)ide analogues could improve the prognosis following percutaneous ablation ${ }^{[147,148,174]}$. Similarly, several studies found that patients with HCV related cirrhosis who have achieved sustained response to antiviral therapy have a substantially lower rate of HCC recurrence after percutaneous ablation in cirrhotic patients with HCC $^{[175]}$. The development of non-invasive methods to assess the degree of liver fibrosis including blood marker tests and transient elastography has revolutionized the assessment of liver fibrosis over the last decade ${ }^{[176]}$. Recent data reported the role of transient elastography in predicting intrahepatic distant recurrence of HCC following $\mathrm{RFA}^{[177]}$. In conclusion, RFA is a potential curative modality for cirrhotic patients with early HCC. Predictors of HCC recurrence after RFA are summarized in Table 2. Additional studies are needed to identify patients with a higher risk of early and late recurrence to improve disease control. 


\section{TRANS-ARTERIAL CHEMOEMBOLIZATION}

TACE, a direct therapy with a minimally invasive catheter, is the most commonly used interventional radiology technique for the first-line treatment of intermediate stage (BCLC-B) and unresectable HCC ${ }^{[178,179]}$. The TACE procedure works on the pathophysiological principle that malignant hepatic lesions receive blood supply from the hepatic artery. Thus, the intra-arterial infusion of a cytotoxic agent followed by embolisation of the blood vessels that feed the tumor leads to a direct cytotoxic and ischemic effect on the tumor mass. HCC, indeed, tends to be fed entirely through the arterial supply, unlike the surrounding parenchyma which receives most of its inflow through the portal system. During TACE procedures, a catheter superselectively places an emulsion of the water-soluble antitumor agent mixed usually with ethiodized oil ${ }^{[180]}$. The effectiveness of TACE is through providing highly concentrated doses of chemotherapy to the tumor bed, while sparing the surrounding liver parenchyma. Conventional TACE, also known as Lipiodol TACE, consists of catheter delivery of the chemotherapeutic emulsified with Lipiodol, followed by vascular stagnation obtained with embolisation of the particles ${ }^{[181]}$. During these procedures, the most commonly used chemotherapy drugs are epirubicin, doxorubicin, miriplatin or cisplatin ${ }^{[181]}$. Besides conventional TACE, other image-guided transcatheter techniques have been developed recently (chemo-lipiodolisation, bland transcatheter embolisation and intra-arterial chemotherapy) but not recommended clinically yet ${ }^{[179]}$. Recently, drug-eluting beads transcatheter arterial chemoembolization (DEB-TACE) has become a routinely used locoregional treatment for unresectable HCC. DEB-TACE have the same clinical outcomes and reduced procedure-related side effects compared to conventional transcatheter arterial chemoembolization ${ }^{[182,183]}$. Many potential factors affecting HCC recurrence after TACE treatment have been investigated in the last decades [Table 2].

\section{Tumor-related factors}

HCC is a hypervascular tumour such that tumour angiogenesis may be essential to its growth, invasion, or metastasis ${ }^{[184,185]}$. The changes induced by TACE in the expression of angiogenic and invasiveness factors [basic fibroblast growth factor (b-FGF), vascular endothelial growth factor (VEGF), urokinasetype plasminogen activator ( $\mathrm{UPA}$ ) and mammalian chitinase-like proteins without chitinase activity (YKL$40-\mathrm{CHI} \mathrm{L}_{1}$ )] have been investigated. These markers work synergically and seem to be overexpressed after TACE as a result of the related ischemic damage, which renders them useful for predicting treatment response to TACE. In fact, when TACE is not adequate, a significant neoangiogenesis reaction happens, as suggested by an increase in VEGF, uPA, b-FGF and YKL-40 following treatment, and affects patient survival ${ }^{[135-138,186]}$. Moreover, the systemic inflammatory response ${ }^{[187]}$ reflects the state of angiogenesis, DNA damage and tumor invasion ${ }^{[188]}$. Among these, systemic immune-inflammation index ${ }^{[143]}$, aspartate aminotransferase-lymphocyte ratio index and CRP/Alb ratio ${ }^{[144]}$ are useful non-invasive biological markers with high negative predictive values for HCC OS after TACE. As a matter of fact, tumor size and portal invasion represent the most well-validated HCC prognostic factors after TACE treatment ${ }^{[132]}$. In $87 \%$ of patients, the low-grade tumors (grade 0,1 , or 2) have shown encouraging long-term treatment response (49\%; stable disease or local disease progression, $13 \%$; partial response, $38 \%$; complete response) vs. $33 \%$ of high-grade tumors (grade 3 or 4 ) (stable disease or disease progression, 67\%; partial response, 33\%; complete response, $0 \%$ ) after TACE ${ }^{[133]}$.

\section{Circulating biomarkers and patients' characteristics}

Several laboratory markers have been associated with prognostic outcomes in HCC patients undergoing TACE. AFP levels and changes ${ }^{[140-142]}$, low pretreatment platelets ${ }^{[189]}$, low baseline serum 25 -hydroxyvitamin (D25-OHD) levels ${ }^{[190]}$, high values of $\mathrm{CRP}^{[138]}$, high levels of serum gamma-glutamyl transferase ${ }^{[191]}$ and high levels of bilirubin ${ }^{[132]}$ are all potentially useful biomarkers to predict the poor prognosis in patients with HCC treated with TACE. Moreover, procalcitonin is a precursor of the hormone calcitonin and usually rises in bacterial infections; it was recently proposed as an important prognostic factor for foretelling the prognosis of patients treated with TACE with unresectable HCC ${ }^{[192]}$. 
More than a dozen staging systems have been described and some have been put into clinical practice for either HCC prognostication or as treatment guidelines ${ }^{[193]}$. Amongst them, the Cancer of the Liver Italian Program (CLIP) score (takes into account liver function reserves and tumor characteristics), and the ALBICLIP grade (consisting of a formula based on albumin and bilirubin) were good predictors of survival up to 2-years after TACE ${ }^{[145,146]}$. The CLIP system was superior to the Okuda system for predicting the survival of patients with unresectable HCC treated with TACE ${ }^{[194]}$. MELD is inferior to the Child-Pugh system in predicting patient survival in those with unresectable HCC after TACE ${ }^{[195]}$. Instead, the CLIP and MELD systems are superior to the Okuda system in predicting the survival of patients with viral hepatitis and unresectable HCC treated with $\mathrm{TACE}^{[196]}$. A nomogram based on AFP, IGC15, portal vein invasion, tumor capsule, AST and the tumor number has been developed and validated in a precise prognostic model in patients treated with TACE for unresectable $\mathrm{HCC}^{[197]}$. Finally, sarcopenia has also been correlated with disease-free survival and poorer OS in patients with $\mathrm{HCC}^{[76]}$. Recently, the rate of change $(<-4.6 \%)$ in skeletal muscle mass $(\triangle \mathrm{L} 3 \mathrm{SMI})$ over six months after TACE has been associated with a poor prognosis ${ }^{[164]}$. Venous ketone bodies, which mirrors muscles status and hepatic reserve function, has been negatively correlated with survival and is thus, a useful predictor of HCC treatment response and prognosis ${ }^{[198]}$.

\section{Molecular and genetics biomarkers}

It has been reported that some patients have developed resistance to chemotherapy drugs in which efficacy becomes greatly reduced and toxicity to normal hepatocytes has grown. Therefore, molecular biomarkers capable of predicting treatment response have been studied to improve chemotherapy efficacy.

Many single nucleotide polymorphism (SNP) have been evaluated as an independent prognosis biomarker for HCC after TACE treatment. The main recently studied SNPs were: SNP rs1126497 in the epithelial cell adhesion/activating molecule $(E P C A M)$ gene ${ }^{[199]}$, multidrug resistance gene 1 (MDR1) C1236T and $C_{3435 T^{[200]} \text {, isocitrate dehydrogenase }(I D H)}$ gene $^{[201]}$, polypeptide $\mathrm{N}$-Acetylgalactosaminyltransferase 14 (GALNT14) "TT" genotype ${ }^{[202]}$ and pri-let-7a-1 ${ }^{[203]}$. Moreover, recently a TACE-specific 14-gene signature has been independently related to early disease-free survival and OS in an Asian cohort of HCC patients and further validated in a European cohort ${ }^{[204]}$.

MicroRNAs in circulating blood have also been studied as prognostic markers in HCC $^{[149,150]}$.

\section{Imaging predictive factors}

There is a notion that imaging techniques (ultrasound, CT and MRI) might facilitate the visualisation and characterization of HCC nodules clearly and accurately. Additionally, it may also aid in displaying perfusion differences between residual carcinoma and necrotic tissue following TACE ablation. Ultrasound techniques, mainly contrast-enhanced ultrasound, can act as a valuable tool to assess the results of TACE and exhibit mostly optimal effects in the early and very early evaluation of $\operatorname{TACE}^{[153,205]}$. More recently, Xuan et al. ${ }^{[138]}$ showed that four contrast-enhanced ultrasound parameters prior to TACE, including time to peak, maximum tumor intensity, washout time, and rise time, were associated with the recurrence and prognosis of HCC after TACE. Time to peak tumor reflected the structure of the blood supply in tumor lesions and was correlated with enhanced tumor metastasis and invasion that can lead to worse survival rates and an unfavourable prognosis ${ }^{[138]}$.

Multi-detector CT is the most commonly used imaging technology for assessing therapeutic response to $\mathrm{TACE}^{[154,156]}$. Patients with hypervascular HCC (defined by an enhancement pattern on the arterial-phase of a CT scan) were more likely to respond to TACE with a reduction in tumor size and increased survival than patients with a less vascular tumor ${ }^{[139]}$; it is also notable that patients with hypervascular HCCs have a survival benefit from TACE, even if they are classified as non-responders by size criteria ${ }^{[157]}$. Other criteria such as higher arterial enhancement and grey-level co-occurrence matrix moments (by dynamic CT texture 
analysis), lower homogeneity, and smaller tumor size are all significant predictors of complete response after $\mathrm{TACE}^{[158]}$.

Recently, in patients with very early and early HCC, the presence of hypovascular hepatic nodules represents a significant risk factor for recurrence and a bad prognosis after treatment; this is a contraindication to the procedure in these patients ${ }^{[159]}$. Moreover, a CT image analysis method known as the parametric response map approach is more sensitive for finding changes in the response to treatment than the conventional approach based on the recap of statistics assessed on a region of interest. Briefly, parametric response map aligns spatially the longitudinal images before and after treatment and classifies the patient's images into three categories: reduced, unchanged, and increased intensity ${ }^{[160]}$.

MRI has a central role in the identification of focal liver lesions. With technical progress, liver MRI has improved with many imaging modalities now for the diagnosis of $\mathrm{HCC}^{[161]}$. Indeed, gadoxetic acid (Primovist, Bayer Schering Pharma) provides dynamic perfusion imaging and also, evaluation of delayed hepatocyte uptake and biliary excretion which concurs with the precise detection and characterisation of HCC $^{[206]}$. Gadoxetic acid-enhanced liver MRI is now widely used and plays a crucial role, not just in the initial diagnosis of HCC, but also in the evaluation of therapeutic efficacy and early diagnosis of residual or recurrent tumor after TACE ${ }^{[207]}$. Indeed, HCCs showing high uptake of gadoxetic acid appear to be susceptible to TACE with increasing HCC free-survival in these patients ${ }^{[162]}$. Combined diffusion-weighted imaging and choline levels measured at hydrogen-1 magnetic resonance spectroscopy can be used as an early imaging biomarker of treatment response in HCC patients after DEB-TACE ${ }^{[163]}$. Moreover, in unresectable HCC, baseline early apparent diffusion coefficients $<0.83 \times 10^{-3} \mathrm{~mm}^{2} / \mathrm{s}$ is a predictor of treatment response at 1 and 3 months after DEB-TACE and OS with high specificity and sensitivity ${ }^{[155]}$. Finally, a sophisticated 3D MRI and CT method based on quantitative tumor response (volumetric Response Evaluation Criteria in Solid Tumors and the European Association for Study of the Liver guidelines) were early response markers that can be used to predict survival after initial TACE and allow univocal identification of responders and non-responders in terms of median $\mathrm{OS}^{[208]}$.

\section{CONCLUSION}

HCC characteristics and the severity of the underlying liver disease are the main considerations in the decision-making process for the best therapeutic strategy for each patient, in order to improve survival and reduce recurrence rates. HCC early recurrence remains related to the aggressiveness of the treated HCC and the technique used. HCC late recurrence, being a "de novo" tumor, is mainly predicted by markers of severity of liver fibrosis and the degree of portal hypertension.

Beyond liver disease etiology and the continuous presence of pro-carcinogenetic factors that are etiologyrelated, the most reliable markers for predicting HCC recurrence after LR are the presence of macro- and micro-vascular invasion, tumor size and the assessment of liver disease severity through the use of LSM. For the same purpose, no definitive data are available in the setting of RFA, even if most studies seem to support a role for LSM. On the other hand, one of the most reliable predictive factors for HCC recurrence after TACE is tumor hypervascularity. The novel circulating, genetic and imaging related markers still need additional validation. Thus, further prospective and well-designed studies are needed to discover new and reliable predictive markers for HCC recurrence after treatments with curative intent.

\section{DECLARATIONS}

\section{Authors' contributions}

Conceptualized and designed the review: Marasco G, Colecchia A

Wrote, reviewed and edited the manuscript: Marasco G, Ravaioli F, Vestito A, Rossini B, Dajti E, Renzulli M

Provided the tables: Rossini B, Colecchia L, Gjini K 
Reviewed and approved the final manuscript as submitted: Marasco G, Colecchia A, Golfieri R, Festi D All authors read and approved the final manuscript.

\section{Availability of data and materials}

Not applicable.

\section{Financial support and sponsorship}

None.

\section{Conflicts of interest}

All authors declared that there are no conflicts of interest.

\section{Ethical approval and consent to participate}

Not applicable.

\section{Consent for publication}

Not applicable.

\section{Copyright}

(c) The Author(s) 2020.

\section{REFERENCES}

1. Llovet JM, Brú C, Bruix J. Prognosis of hepatocellular carcinoma: the BCLC staging classification. Semin Liver Dis 1999;19:329-38.

2. European Association for the Study of the Liver. EASL Clinical Practice Guidelines: management of hepatocellular carcinoma. J Hepatol 2018;69:182-236.

3. Kanwal F, Kramer JR, Asch SM, Cao Y, Li L, et al. Long-term risk of hepatocellular carcinoma in HCV patients treated with direct acting antiviral agents. Hepatology 2020;71:44-55.

4. Heimbach JK, Kulik LM, Finn RS, Sirlin CB, Abecassis MM, et al. AASLD guidelines for the treatment of hepatocellular carcinoma. Hepatology 2018;67:358-80.

5. Dufour JF, Greten TF, Raymond E, Roskams T, De T, et al. Clinical practice guidelines EASL - EORTC clinical practice guidelines: management of hepatocellular carcinoma European Organisation for Research and Treatment of Cancer. J Hepatol 2012;56:908-43.

6. Omata M, Cheng AL, Kokudo N, Kudo M, Lee JM, et al. Asia-Pacific clinical practice guidelines on the management of hepatocellular carcinoma: a 2017 update. Hepatol Int 2017;11:317-70.

7. Bruix J, Reig M, Sherman M. Evidence-based diagnosis, staging, and treatment of patients with hepatocellular carcinoma. Gastroenterology 2016;150:835-53.

8. Colecchia A, Schiumerini R, Cucchetti A, Cescon M, Taddia M, et al. Prognostic factors for hepatocellular carcinoma recurrence. World J Gastroenterol 2014;20:5935-50.

9. D'Amico G, Garcia-Tsao G, Pagliaro L. Natural history and prognostic indicators of survival in cirrhosis: a systematic review of 118 studies. J Hepatol 2006;44:217-31.

10. Zhou JY, Zhang L, Li L, Gu GY, Zhou YH, et al. High hepatitis B virus load is associated with hepatocellular carcinomas development in Chinese chronic hepatitis B patients: a case control study. Virol J 2012;9:16.

11. Poon RT, Fan ST, Ng IO, Lo CM, Liu CL, et al. Different risk factors and prognosis for early and late intrahepatic recurrence after resection of hepatocellular carcinoma. Cancer 2000;89:500-7.

12. Tung-Ping Poon R, Fan ST, Wong J. Risk factors, prevention, and management of postoperative recurrence after resection of hepatocellular carcinoma. Ann Surg 2000;232:10-24.

13. Imamura $\mathrm{H}$, Matsuyama $\mathrm{Y}$, Tanaka $\mathrm{E}$, Ohkubo $\mathrm{T}$, Hasegawa $\mathrm{K}$, et al. Risk factors contributing to early and late phase intrahepatic recurrence of hepatocellular carcinoma after hepatectomy. J Hepatol 2003;38:200-7.

14. Llovet JM, Schwartz M, Mazzaferro V. Resection and liver transplantation for hepatocellular carcinoma. Semin Liver Dis 2005;25:181200.

15. Qu LS, Liu JX, Zhu J, Lu CH. Risk factors for prognosis of hepatocellular carcinoma after curative resection in patients with low hepatitis B viral load. Ann Hepatol 2017;16:412-20.

16. Jung KS, Kim JH, Kim SU, Song K, Kim BK, et al. Liver stiffness value-based risk estimation of late recurrence after curative resection of hepatocellular carcinoma: Development and validation of a predictive model. PLoS One 2014;9:e99167.

17. Marasco G, Colecchia A, Colli A, Ravaioli F, Casazza G, et al. Role of liver and spleen stiffness in predicting the recurrence of hepatocellular carcinoma after resection. J Hepatol 2019;70:440-8. 
18. Yamamoto Y, Ikoma H, Morimura R, Konishi H, Murayama Y, et al. Optimal duration of the early and late recurrence of hepatocellular carcinoma after hepatectomy. World J Gastroenterol 2015;21:1207-15.

19. Roayaie S, Blume IN, Thung SN, Guido M, Fiel MI, et al. A system of classifying microvascular invasion to predict outcome after resection in patients with hepatocellular carcinoma. Gastroenterology 2009;137:850-5.

20. Pawlik TM, Esnaola NF, Vauthey JN. Surgical treatment of hepatocellular carcinoma: similar long-term results despite geographic variations. Liver Transpl 2004;10:S74-80.

21. Ripoll C, Groszmann R, Garcia-Tsao G, Grace N, Burroughs A, et al. Hepatic venous pressure gradient predicts clinical decompensation in patients with compensated cirrhosis. Gastroenterology 2007;133:481-8.

22. Colecchia A, Colli A, Casazza G, Mandolesi D, Schiumerini R, et al. Spleen stiffness measurement can predict clinical complications in compensated HCV-related cirrhosis: a prospective study. J Hepatol 2014;60:1158-64.

23. Colecchia A, Marasco G, Taddia M, Montrone L, Eusebi LH, et al. Liver and spleen stiffness and other noninvasive methods to assess portal hypertension in cirrhotic patients: a review of the literature. Eur J Gastroenterol Hepatol 2015;27:992-1001.

24. Colecchia A, Ravaioli F, Marasco G, Festi D. Spleen stiffness by ultrasound elastography. In: Berzigotti A, Bosch J, editors. Diagnostic methods for cirrhosis and portal hypertension. Cham, Springer International Publishing; 2018. pp. 113-37.

25. Ripoll C, Groszmann RJ, Garcia-Tsao G, Bosch J, Grace N, et al. Hepatic venous pressure gradient predicts development of hepatocellular carcinoma independently of severity of cirrhosis. J Hepatol 2009;50:923-8.

26. Jung KS, Kim SU, Choi GH, Park JY, Park YN, et al. Prediction of recurrence after curative resection of hepatocellular carcinoma using liver stiffness measurement (FibroScan $\left.{ }^{\circledR}\right)$. Ann Surg Oncol 2012;19:4278-86.

27. Kamiyama T, Nakanishi K, Yokoo H, Kamachi H, Tahara M, et al. Analysis of the risk factors for early death due to disease recurrence or progression within 1 year after hepatectomy in patients with hepatocellular carcinoma. World J Surg Oncol 2012;10:107.

28. Liu L, Miao R, Yang H, Lu X, Zhao Y, et al. Prognostic factors after liver resection for hepatocellular carcinoma: a single-center experience from China. Am J Surg 2012;203:741-50.

29. Pawlik TM, Delman KA, Vauthey JN, Nagorney DM, Ng IOL, et al. Tumor size predicts vascular invasion and histologic grade: Implications for selection of surgical treatment for hepatocellular carcinoma. Liver Transplant 2005;11:1086-92.

30. Colecchia A, Scaioli E, Montrone L, Vestito A, Di Biase AR, et al. Pre-operative liver biopsy in cirrhotic patients with early hepatocellular carcinoma represents a safe and accurate diagnostic tool for tumour grading assessment. J Hepatol 2011;54:300-5.

31. Pawlik TM, Gleisner AL, Anders RA, Assumpcao L, Maley W, et al. Preoperative assessment of hepatocellular carcinoma tumor grade using needle biopsy. Ann Surg 2007;245:435-42.

32. Jung SM, Kim JM, Choi GS, Kwon CHD, Yi NJ, et al. Characteristics of early recurrence after curative liver resection for solitary hepatocellular carcinoma. J Gastrointest Surg 2019;23:304-11.

33. Lau WY, Sangro B, Chen PJ, Cheng SQ, Chow P, et al. Treatment for hepatocellular carcinoma with portal vein tumor thrombosis: the emerging role for radioembolization using yttrium-90. Oncology 2013;84:311-8.

34. Mazzaferro V, Sposito C, Bhoori S, Romito R, Chiesa C, et al. Yttrium-90 radioembolization for intermediate-advanced hepatocellular carcinoma: a phase 2 study. Hepatology 2013;57:1826-37.

35. Hirokawa F, Hayashi M, Miyamoto Y, Asakuma M, Shimizu T, et al. Outcomes and predictors of microvascular invasion of solitary hepatocellular carcinoma. Hepatol Res 2014;44:846-53.

36. Kaibori M, Ishizaki M, Matsui K, Kwon AH. Predictors of microvascular invasion before hepatectomy for hepatocellular carcinoma. J Surg Oncol 2010;102:462-8.

37. Rodríguez-Perálvarez M, Luong TV, Andreana L, Meyer T, Dhillon AP, et al. A systematic review of microvascular invasion in hepatocellular carcinoma: Diagnostic and prognostic variability. Ann Surg Oncol 2013;20:325-39.

38. Kim JM, Joh JW, Yi NJ, Choi GS, Kim K, et al. Predicting hepatocellular carcinoma recurrence beyond milan criteria after liver resection for solitary hepatocellular carcinoma. J Gastrointest Surg 2019; Epub ahead of print. doi: 10.1007/s11605-019-04363-1.

39. Zhao H, Hua Y, Lu Z, Gu S, Zhu L, et al. Prognostic value and preoperative predictors of microvascular invasion in solitary hepatocellular carcinoma $\leq 5 \mathrm{~cm}$ without macrovascular invasion. Oncotarget 2017;8:61203-14.

40. Cucchetti A, Cescon M, Ercolani G, Bigonzi E, Torzilli G, et al. A comprehensive meta-regression analysis on outcome of anatomic resection versus nonanatomic resection for hepatocellular carcinoma. Ann Surg Oncol 2012;19:3697-705.

41. Shi M, Guo RP, Lin XJ, Zhang YQ, Chen MS, et al. Partial hepatectomy with wide versus narrow resection margin for solitary hepatocellular carcinoma. Ann Surg 2007;245:36-43.

42. Lai ECS, You KT, Ng IOL, Shek TWH. The pathological basis of resection margin for hepatocellular carcinoma. World J Surg 1993;17:786-90.

43. Tsilimigras DI, Sahara K, Moris D, Hyer JM, Paredes AZ, et al. Effect of surgical margin width on patterns of recurrence among patients undergoing R0 hepatectomy for T1 hepatocellular carcinoma: an international multi-institutional analysis. J Gastrointest Surg 2019; Epub ahead of print. doi: 10.1007/s11605-019-04275-0.

44. Belghiti J, Panis Y, Farges O, Benhamou JP, Fekete F. Intrahepatic recurrence after resection of hepatocellular carcinoma complicating cirrhosis. Ann Surg 1991;214:114-7.

45. Guo Y, Chua DW, Koh YX, Lee SY, Cheow PC, et al. Preoperative predictors including the role of inflammatory indices in predicting early recurrence after re-resection for recurrent hepatocellular carcinoma. World J Surg 2019;43:2587-94.

46. Tabrizian P, Jibara G, Shrager B, Schwartz M, Roayaie S. Recurrence of hepatocellular cancer after resection: patterns, treatments, and prognosis. Ann Surg 2015;261:947-55.

47. Zhang X, Bai Y, Xu L, Zhang B, Feng S, et al. Clinical and morpho-molecular classifiers for prediction of hepatocellular carcinoma 
prognosis and recurrence after surgical resection. Hepatol Int 2019;13:715-25.

48. Liao M, Chen P, Liao Y, Li J, Yao W, et al. Preoperative high-sensitivity C-reactive protein to lymphocyte ratio index plays a vital role in the prognosis of hepatocellular carcinoma after surgical resection. Onco Targets Ther 2018;11:5591-600.

49. Hung HC, Lee JC, Cheng CH, Wu TH, Wang YC, et al. Impact of neutrophil to lymphocyte ratio on survival for hepatocellular carcinoma after curative resection. J Hepatobiliary Pancreat Sci 2017;24:559-69.

50. Zheng J, Cai J, Li H, Zeng K, He L, et al. Neutrophil to lymphocyte ratio and platelet to lymphocyte ratio as prognostic predictors for hepatocellular carcinoma patients with various treatments: a meta-analysis and systematic review. Cell Physiol Biochem 2017;44:967-81.

51. Itoh S, Yugawa K, Shimokawa M, Yoshiya S, Mano Y, et al. Prognostic significance of inflammatory biomarkers in hepatocellular carcinoma following hepatic resection. BJS Open 2019;3:500-8.

52. Liao M, Qin W, Liao Y, Yao R, Yu J, et al. Prognostic value of gamma-glutamyl transpeptidase to lymphocyte count ratio in patients with single tumor size $\leq 5 \mathrm{~cm}$ hepatocellular carcinoma after radical resection. Front Oncol 2019;9:347.

53. Shi S, Chen Q, Ye L, Yin D, Li X, et al. Prognostic value of systemic inflammation score in patients with hepatocellular carcinoma after hepatectomy. Oncotarget 2017;8:79366-75.

54. Wu J, Ma XL, Tian L, Zhang CY, Wang BL, et al. Serum IgG4: IgG ratio predicts recurrence of patients with hepatocellular carcinoma after curative resection. J Cancer 2017;8:1338-46.

55. Chan AWH, Zhong J, Berhane S, Toyoda H, Cucchetti A, et al. Development of pre and post-operative models to predict early recurrence of hepatocellular carcinoma after surgical resection. J Hepatol 2018;69:1284-93.

56. Tokumitsu Y, Sakamoto K, Tokuhisa Y, Matsui H, Matsukuma S, et al. A new prognostic model for hepatocellular carcinoma recurrence after curative hepatectomy. Oncol Lett 2018;15:4411-22.

57. Cabibbo G, Petta S, Calvaruso V, Cacciola I, Cannavò MR, et al.; Rete Sicilia Selezione Terapia - HCV (RESIST-HCV). Is early recurrence of hepatocellular carcinoma in $\mathrm{HCV}$ cirrhotic patients affected by treatment with direct-acting antivirals? A prospective multicentre study. Aliment Pharmacol Ther 2017;46:688-95.

58. Petta S, Cabibbo G, Barbara M, Attardo S, Bucci L, et al. Hepatocellular carcinoma recurrence in patients with curative resection or ablation: impact of HCV eradication does not depend on the use of interferon. Aliment Pharmacol Ther 2017;45:160-8.

59. Singal AG, Rich NE, Mehta N, Branch A, Pillai A, et al. Direct-acting antiviral therapy not associated with recurrence of hepatocellular carcinoma in a multicenter North American cohort study. Gastroenterology 2019;156:1683-92.e1.

60. Conti F, Buonfiglioli F, Scuteri A, Crespi C, Bolondi L, et al. Early occurrence and recurrence of hepatocellular carcinoma in HCV-related cirrhosis treated with direct-acting antivirals. J Hepatol 2016;65:727-33.

61. Wu JC, Huang YH, Chau GY, Su CW, Lai CR, et al. Risk factors for early and late recurrence in hepatitis B-related hepatocellular carcinoma. J Hepatol 2009;51:890-7.

62. Donato F, Tagger A, Gelatti U, Parrinello G, Boffetta P, et al. Alcohol and hepatocellular carcinoma: the effect of lifetime intake and hepatitis virus infections in men and women. Am J Epidemiol 2002;155:323-31.

63. Kudo A, Tanaka S, Ban D, Matsumura S, Irie T, et al. Alcohol consumption and recurrence of non-B or non-C hepatocellular carcinoma after hepatectomy: a propensity score analysis. J Gastroenterol 2014;49:1352-61.

64. Bai F, Zhou H, Ma M, Guan C, Lyu J, et al. A novel RNA sequencing-based miRNA signature predicts with recurrence and outcome of hepatocellular carcinoma. Mol Oncol 2018;12:1125-37.

65. Vasuri F, Fittipaldi S, De Pace V, Gramantieri L, Bertuzzo V, et al. Tissue miRNA 483-3p expression predicts tumor recurrence after surgical resection in histologically advanced hepatocellular carcinomas. Oncotarget 2018;9:17895-905.

66. Oh J, Lee JM, Park J, Joo I, Yoon JH, et al. Hepatocellular carcinoma: Texture analysis of preoperative computed tomography images can provide markers of tumor grade and disease-free survival. Korean J Radiol 2019;20:569-79.

67. Lee S, Kim SH, Hwang JA, Lee JE, Ha SY. Pre-operative ADC predicts early recurrence of HCC after curative resection. Eur Radiol 2019;29:1003-12.

68. Rimola J, Forner A, Sapena V, Llarch N, Darnell A, et al. Performance of gadoxetic acid MRI and diffusion-weighted imaging for the diagnosis of early recurrence of hepatocellular carcinoma. Eur Radiol 2020;30:186-94.

69. Ahn SJ, Kim JH, Park SJ, Kim ST, Han JK. Hepatocellular carcinoma: preoperative gadoxetic acid-enhanced MR imaging can predict early recurrence after curative resection using image features and texture analysis. Abdom Radiol 2019;44:539-48.

70. Lee S, Kim SH, Lee JE, Sinn DH, Park CK. Preoperative gadoxetic acid-enhanced MRI for predicting microvascular invasion in patients with single hepatocellular carcinoma. J Hepatol 2017;67:526-34.

71. Shan Q, Hu H, Feng S, Peng Z, Chen S, et al. CT-based peritumoral radiomics signatures to predict early recurrence in hepatocellular carcinoma after curative tumor resection or ablation. Cancer Imaging 2019;19:11.

72. Lambin P, Rios-Velazquez E, Leijenaar R, Carvalho S, Van Stiphout RGPM, et al. Radiomics: extracting more information from medical images using advanced feature analysis. Eur J Cancer 2012;48:441-6.

73. Kim S, Shin J, Kim DY, Choi GH, Kim MJ, et al. Radiomics on gadoxetic acid-enhanced magnetic resonance imaging for prediction of postoperative early and late recurrence of single hepatocellular carcinoma. Clin Cancer Res 2019;25:3847-55.

74. Zheng J, Chakraborty J, Chapman WC, Gerst S, Gonen M, et al. Preoperative prediction of microvascular invasion in hepatocellular carcinoma using quantitative image analysis. J Am Coll Surg 2017;225:778-88.e1.

75. Wang J, Shan Q, Liu Y, Yang H, Kuang S, et al. 3D MR elastography of hepatocellular carcinomas as a potential biomarker for predicting tumor recurrence. J Magn Reson Imaging 2019;49:719-30.

76. Fujiwara N, Nakagawa H, Kudo Y, Tateishi R, Taguri M, et al. Sarcopenia, intramuscular fat deposition, and visceral adiposity independently predict the outcomes of hepatocellular carcinoma. J Hepatol 2015;63:131-40. 
77. Lee JI, Lee HW, Kim SU, Ahn SH, Lee KS. Follow-up liver stiffness measurements after liver resection influence oncologic outcomes of hepatitis-b-associated hepatocellular carcinoma with liver cirrhosis. Cancers (Basel) 2019;11:425.

78. Zhang J, Luo Y, Li C, Liu J, Xiang H, et al. The combination of the preoperative albumin-bilirubin grade and the fibrosis-4 index predicts the prognosis of patients with hepatocellular carcinoma after liver resection. Biosci Trends 2019;13:351-7.

79. Johnson PJ, Berhane S, Kagebayashi C, Satomura S, Teng M, et al. A nssessment of liver function in patients with hepatocellular carcinoma: a new evidence-based approach - the albi grade. J Clin Oncol 2015;33:550-8.

80. Lee YH, Koh YS, Hur YH, Cho CK, Kim HJ, et al. Effectiveness of the albumin-bilirubin score as a prognostic factor for early recurrence after curative hepatic resection for hepatocellular carcinoma. Ann Hepato-Biliary-Pancreatic Surg 2018;22:335.

81. Amisaki M, Uchinaka E, Morimoto M, Tokuyasu N, Sakamoto T, et al. Post-operative albumin-bilirubin grade predicts long-term outcomes among Child-Pugh grade A patients with hepatocellular carcinoma after curative resection. Hepatobiliary Pancreat Dis Int 2018;17:502-9.

82. Matsushima H, Takami Y, Ryu T, Yoshitomi M, Tateishi M, et al. Prognosis of hepatocellular carcinoma patients who achieved long-term recurrence-free survival after curative therapy: impact of the ALBI grade. J Gastrointest Surg 2018;22:1230-8.

83. Johnson PJ, Berhane S, Kagebayashi C, Satomura S, Teng M, et al. Assessment of liver function in patients with hepatocellular carcinoma: a new evidence-based approach-the ALBI grade. J Clin Oncol 2015;33:550-8.

84. Lin CY, Lin CC, Wang CC, Chen CL, Hu TH, et al. The ALBI grade is a good predictive model for very late recurrence in patients with hepatocellular carcinoma undergoing primary resection. World J Surg 2020;44:247-57.

85. Lin CW, Chen YS, Lin CC, Lee PH, Lo GH, et al. Clinical and translational gastroenterology autophagy-related gene LC3 expression in tumor and liver microenvironments significantly predicts recurrence of hepatocellular carcinoma after surgical resection. Clin Transl Gastroenterol 2018;9:166.

86. Song Q, Chen X, Hu W, Mei G, Yang X, et al. Downregulation of epstein-barr virus-induced gene 3 is associated with poor prognosis of hepatocellular carcinoma after curative resection. Oncol Lett 2018;15:7751-9.

87. Fang Y, He J, Janssen HLA, Wu J, Dong L, et al. Peroxiredoxin 1, restraining cell migration and invasion, is involved in hepatocellular carcinoma recurrence. J Dig Dis 2018;19:155-69.

88. Hoki T, Katsuta E, Yan L, Takabe K, Ito F. Low DMT1 expression associates with increased oxidative phosphorylation and early recurrence in hepatocellular carcinoma. J Surg Res 2019;234:343-52.

89. Chang YY, Yen CJ, Chan SH, Chou YW, Lee YP, et al. NEK2 promotes hepatoma metastasis and serves as biomarker for high recurrence risk after hepatic resection. Ann Hepatol 2018;17:843-56.

90. Ji F, Zhang Z, Zhang Y, Shen SL, Cao QH, et al. Low expression of c-Myc protein predicts poor outcomes in patients with hepatocellular carcinoma after resection. BMC Cancer 2018;18:460.

91. Huang CF, Wang SC, Chang WT, Yeh ML, Huang CI, et al. Lower protein expression levels of MHC class I chain-related gene A in hepatocellular carcinoma are at high risk of recurrence after surgical resection. Sci Rep 2018;8:15821.

92. Lv Y, Wei W, Huang Z, Chen Z, Fang Y, et al. Long non-coding RNA expression profile can predict early recurrence in hepatocellular carcinoma after curative resection. Hepatol Res 2018;48:1140-8.

93. Wang Y, Tan PY, Handoko YA, Sekar K, Shi M, et al. NUF2 is a valuable prognostic biomarker to predict early recurrence of hepatocellular carcinoma after surgical resection. Int J Cancer 2019;145:662-70.

94. Gao XH, Zhang SS, Chen H, Wang K, Xie W, et al. Lipoprotein (A): a promising prognostic biomarker in patients with hepatocellular carcinoma after curative resection. Onco Targets Ther 2018;11:5917-24.

95. Xu Q, Yan Y, Gu S, Mao K, Zhang J, et al. A novel inflammation-based prognostic score: The fibrinogen/albumin ratio predicts prognoses of patients after curative resection for hepatocellular carcinoma. J Immunol Res 2018;2018:4925498.

96. Oh TK, Choi YR, Cho JY, Yoon YS, Han HS, et al. The high-sensitivity C-reactive protein/albumin ratio predicts long-term oncologic outcomes after curative resection for hepatocellular carcinoma. J Clin Med 2018;7:139.

97. Li C, Zhang XY, Peng W, Wen TF, Yan LN, et al. Preoperative albumin-bilirubin grade plus platelet-to-lymphocyte ratio predict the outcomes of patients with BCLC stage A hepatocellular carcinoma after liver resection. Medicine (Baltimore) 2018;97:e11599.

98. Abbate V, Marcantoni M, Giuliante F, Vecchio FM, Gatto I, et al. HepPar1-positive circulating microparticles are increased in subjects with hepatocellular carcinoma and predict early recurrence after liver resection. Int J Mol Sci 2017;18:1043.

99. Aryal B, Yamakuchi M, Shimizu T, Kadono J, Furoi A, et al. Predictive value of diminished serum PDGF-BB after curative resection of hepatocellular cancer. J Oncol 2019;2019:1925315.

100. Liu H, Chen H, Wu X, Sun Y, Wang Y, et al. The serum proteomics tracking of hepatocellular carcinoma early recurrence following radical resection. Cancer Manag Res 2019;11:2935-46.

101. Toyoda H, Kumada T, Tada T, Kaneoka Y, Maeda A, et al. Serum WFA+-M2BP levels as a prognostic factor in patients with early hepatocellular carcinoma undergoing curative resection. Liver Int 2016;36:293-301.

102. Kim HS, Kim SU, Kim BK, Park JY, Kim DY, et al. Serum Wisteria floribunda agglutinin-positive human Mac-2 binding protein level predicts recurrence of hepatitis B virus-related hepatocellular carcinoma after curative resection. Clin Mol Hepatol 2020;26:33-44.

103. Lee JH, Park JY, Kim DY, Ahn SH, Han KH, et al. Prognostic value of 18F-FDG PET for hepatocellular carcinoma patients treated with sorafenib. Liver Int 2011;31:1144-9.

104. Cescon M, Colecchia A, Cucchetti A, Peri E, Montrone L, et al. Value of transient elastography measured with fibroscan in predicting the outcome of hepatic resection for hepatocellular carcinoma. Ann Surg 2012;256:706-13.

105. Eguchi S, Kanematsu T, Arii S, Okazaki M, Okita K, et al.; Liver Cancer Study Group of Japan. Comparison of the outcomes between an anatomical subsegmentectomy and a non-anatomical minor hepatectomy for single hepatocellular carcinomas based on a Japanese 
nationwide survey. Surgery 2008;143:469-75.

106. Xu XF, Xing H, Han J, Li ZL, Lau WY, et al. Risk factors, patterns, and outcomes of late recurrence after liver resection for hepatocellular carcinoma: a multicenter study from China. In: JAMA Surg 2019;154:209-17.

107. Chan EEH, Chow PKH. A review of prognostic scores after liver resection in hepatocellular carcinoma: the MSKCC, SLICER and SSCLIP scores. Jpn J Clin Oncol 2016;47:287-93.

108. Testino G, Leone S, Borro P. Alcohol and hepatocellular carcinoma: a review and a point of view. World J Gastroenterol 2014;20:1594354.

109. Shinkawa H, Tanaka S, Takemura S, Ito T, Aota T, et al. Obesity and recurrence-free survival in patients with hepatocellular carcinoma after achieving sustained virological response to interferon therapy for chronic hepatitis C. Ann Gastroenterol Surg 2018;2:319-26.

110. Qin W, Wang L, Hu B, Leng S, Tian H, et al. A novel score predicts HBV-related hepatocellular carcinoma recurrence after hepatectomy: a retrospective multicenter study. J Gastrointest Surg 2019;23:922-32.

111. Colecchia A, Montrone L, Scaioli E, Bacchi-Reggiani ML, Colli A, et al. Measurement of spleen stiffness to evaluate portal hypertension and the presence of esophageal varices in patients with HCV-related cirrhosis. Gastroenterology 2012 ; 143:646-54.

112. Festi D, Dajti E, Ravaioli F, Marasco G, Colecchia A. Role and clinical meaning of non-invasive tests in the evaluation of portal hypertension in patients with advanced chronic liver disease. Recenti Prog Med 2018;109:574-84.

113. Marasco G, Colecchia A, Dajti E, Ravaioli F, Cucchetti A, et al. Prediction of posthepatectomy liver failure: role of SSM and LSPS. J Surg Oncol 2019;119:400-1.

114. Korean Liver Cancer Association (KLCA); National Cancer Center (NCC). 2018 Korean liver cancer association-national cancer center korea practice guidelines for the management of hepatocellular carcinoma. Korean J Radiol 2019;20:1042-113.

115. Livraghi T, Festi D, Monti F, Salmi A, Vettori C. US-guided percutaneous alcohol injection of small hepatic and abdominal tumors. Radiology 1986;161:309-12.

116. Shiina S, Tateishi R, Imamura M, Teratani T, Koike Y, et al. Percutaneous ethanol injection for hepatocellular carcinoma: 20-year outcome and prognostic factors. Liver Int 2012;32:1434-42.

117. Bruix J, Sherman M. Management of hepatocellular carcinoma. Hepatology 2005;42:1208-36.

118. Khan KN, Yatsuhashi H, Yamasaki K, Yamasaki M, Inoue O, et al. Prospective analysis of risk factors for early intrahepatic recurrence of hepatocellular carcinoma following ethanol injection. J Hepatol 2000;32:269-78.

119. Germani G, Pleguezuelo M, Gurusamy K, Meyer T, Isgrò G, et al. Clinical outcomes of radiofrequency ablation, percutaneous alcohol and acetic acid injection for hepatocelullar carcinoma: a meta-analysis. J Hepatol 2010;52:380-8.

120. Ebara M, Okabe S, Kita K, Sugiura N, Fukuda H, et al. Percutaneous ethanol injection for small hepatocellular carcinoma: Therapeutic efficacy based on 20-year observation. J Hepatol 2005;43:458-64.

121. Koda M, Murawaki Y, Mitsuda A, Ohyama K, Horie Y, et al. Predictive factors for intrahepatic recurrence after percutaneous ethanol injection therapy for small hepatocellular carcinoma. Cancer 2000;88:529-37.

122. Ohnishi K, Yoshioka H, Ito S, Fujiwara K. Prospective randomized controlled trial comparing percutaneous acetic acid injection and percutaneous ethanol injection for small hepatocellular carcinoma. Hepatology 1998;27:67-72.

123. Shiina S, Tagawa K, Unuma T, Takanashi R, Yoshiura K, et al. Percutaneous ethanol injection therapy for hepatocellular carcinoma. a histopathologic study. Cancer 1991;68:1524-30.

124. Lin SM, Lin CJ, Lin CC, Hsu CW, Chen YC. Radiofrequency ablation improves prognosis compared with ethanol injection for hepatocellular carcinoma $\leq 4 \mathrm{~cm}$. Gastroenterology 2004;127:1714-23.

125. Lin SM, Lin CJ, Lin CC, Hsu CW, Chen YC. Randomised controlled trial comparing percutaneous radiofrequency thermal ablation, percutaneous ethanol injection, and percutaneous acetic acid injection to treat hepatocellular carcinoma of $3 \mathrm{~cm}$ or less. Gut 2005;54:1151-6.

126. Hines-Peralta A, Liu ZJ, Horkan C, Solazzo S, Goldberg SN. Chemical tumor ablation with use of a novel multiple-tine infusion system in a canine sarcoma model. J Vasc Interv Radiol 2006;17:351-8.

127. Livraghi T, Meloni F, Di Stasi M, Rolle E, Solbiati L, et al. Sustained complete response and complications rates after radiofrequency ablation of very early hepatocellular carcinoma in cirrhosis: is resection still the treatment of choice? Hepatology 2008;47:82-9.

128. Lencioni R, Crocetti L. Local-regional treatment of hepatocellular carcinoma. Radiology 2012;262:43-58.

129. Lurje I, Czigany Z, Bednarsch J, Roderburg C, Isfort P, et al. Treatment strategies for hepatocellular carcinoma - a multidisciplinary approach. Int J Mol Sci 2019;20:1465.

130. Ganne-Carrié N, Nault JC, Ziol M, N'Kontchou G, Nahon P, et al. Predicting recurrence following radiofrequency percutaneous ablation for hepatocellular carcinoma. Hepatic Oncol 2014;1:395-408.

131. Zytoon AA, Ishii H, Murakami K, El-kholy MR, Furuse J, et al. Recurrence-free survival after radiofrequency ablation of hepatocellular carcinoma. A registry report of the impact of risk factors on outcome. Jpn J Clin Oncol 2007;37:658-72.

132. Bruix J, Sala M, Llovet JM. Chemoembolization for hepatocellular carcinoma. Gastroenterology 2004;127:S179-88.

133. Sandow TA, Arndt SE, Albar AA, DeVun DA, Kirsch DS, et al. Assessment of response to transcatheter arterial chemoembolization with doxorubicin-eluting microspheres: tumor biology and hepatocellular carcinoma recurrence in a 5-year transplant cohort. Radiology 2018;286:1072-83.

134. Yamakado K, Takaki H, Nakatsuka A, Yamaknaka T, Fujimori M, et al. Radiofrequency ablation for hepatocellular carcinoma. Gastrointest Interv 2014;3:35-9.

135. Poon RTP, Lau C, Yu WC, Fan ST, Wong J. High serum levels of vascular endothelial growth factor predict poor response to transarterial chemoembolization in hepatocellular carcinoma: a prospective study. Oncol Rep 2004;11:1077-84. 
136. Liao X, Yi J, Li X, Yang Z, Deng W, et al. Expression of angiogenic factors in hepatocellular carcinoma after transcatheter arterial chemoembolization. J Huazhong Univ Sci Technolog Med Sci 2003;23:280-2.

137. Sergio A, Cristofori C, Cardin R, Pivetta G, Ragazzi R, et al. TTranscatheter arterial chemoembolization (TACE) in hepatocellular carcinoma (HCC): the role of angiogenesis and invasiveness. Am J Gastroenterol 2008;103:914-21.

138. Xuan ZD, Zhou L, Wang Y, Zheng X. Prognostic value of the combination of serum levels of vascular endothelial growth factor, $\mathrm{C}$-reactive protein and contrast-enhanced ultrasound in patients with primary liver cancer who underwent transcatheter arterial chemoembolization. Expert Rev Anticancer Ther 2017;17:1169-78.

139. Katyal S, Oliver JH, Peterson MS, Chang PJ, Baron RL, et al. Prognostic significance of arterial phase CT for prediction of response to transcatheter arterial chemoembolization in unresectable hepatocellular carcinoma: a retrospective analysis. Am J Roentgenol 2000; $175: 1665-72$.

140. Lee YK, Kim SU, Kim DY, Ahn SH, Lee KH, et al. Prognostic value of $\alpha$-fetoprotein and des- $\gamma$-carboxy prothrombin responses in patients with hepatocellular carcinoma treated with transarterial chemoembolization. BMC Cancer 2013;13:5.

141. Kim BK, Ahn SH, Seong JS, Park JY, Kim DY, et al. Early $\alpha$-fetoprotein response as a predictor for clinical outcome after localized concurrent chemoradiotherapy for advanced hepatocellular carcinoma. Liver Int 2011;31:369-76.

142. Riaz A, Ryu RK, Kulik LM, Mulcahy MF, Lewandowski RJ, et al. Alpha-fetoprotein response after locoregional therapy for hepatocellular carcinoma: oncologic marker of radiologic response, progression, and survival. J Clin Oncol 2009;27:5734-42.

143. Yang Z, Zhang J, Lu Y, Xu Q, Tang B, et al. Aspartate aminotransferase-lymphocyte ratio index and systemic immune-inflammation index predict overall survival in HBV-related hepatocellular carcinoma patients after transcatheter arterial chemoembolizations. Oncotarget 2015;6:43090-8.

144. Shen Y, Wang H, Li W, Chen J. Prognostic significance of the CRP/Alb and neutrophil to lymphocyte ratios in hepatocellular carcinoma patients undergoing TACE and RFA. J Clin Lab Anal 2019;33:e22999.

145. Cai XR, Chen ZH, Liu MM, Lin JX, Zhang XP, et al. Modified CLIP score with the albumin-bilirubin grade retains prognostic value in HBV-related hepatocellular carcinoma patients treated with trans-catheter arterial chemoembolization therapy. J Cancer 2018;9:2380-8.

146. Kim JH, Sinn DH, Lee JH, Hyun D, Cho SK, et al. Novel albumin-bilirubin grade-based risk prediction model for patients with hepatocellular carcinoma undergoing chemoembolization. Dig Dis Sci 2018;63:1062-71.

147. Chung GE, Kim W, Lee JH, Kim YJ, Yoon JH, et al. Negative hepatitis B envelope antigen predicts intrahepatic recurrence in hepatitis B virus-related hepatocellular carcinoma after ablation therapy. J Gastroenterol Hepatol 2011;26:1638-45.

148. Sohn W, Paik YH, Lee MW, Rhim H, Lim HK, et al. Predisposing factors for recurrence of HBV-related small hepatocellular carcinoma after percutaneous radiofrequency ablation. Scand J Gastroenterol 2014;49:373-80.

149. Kim SS, Nam JS, Cho HJ, Won JH, Kim JW, et al. Plasma micoRNA-122 as a predictive marker for treatment response following transarterial chemoembolization in patients with hepatocellular carcinoma. J Gastroenterol Hepatol 2017;32:199-207.

150. Cui L, Hu Y, Bai B, Zhang S. Serum miR-335 level is associated with the treatment response to trans-arterial chemoembolization and prognosis in patients with hepatocellular carcinoma. Cell Physiol Biochem 2015;37:276-83.

151. Lu YL, Yao JG, Huang XY, Wang C, Wu XM, et al. Prognostic significance of miR-1268a expression and its beneficial effects for postoperative adjuvant transarterial chemoembolization in hepatocellular carcinoma. Sci Rep 2016;6:36104.

152. Ali HEA, Emam AA, Zeeneldin AA, Srour R, Tabashy R, et al. Circulating miR-26a, miR-106b, miR-107 and miR-133b stratify hepatocellular carcinoma patients according to their response to transarterial chemoembolization. Clin Biochem 2019;65:45-52.

153. Gao Y, Zheng DY, Cui Z, Ma Y, Liu YZ, et al. Predictive value of quantitative contrast-enhanced ultrasound in hepatocellular carcinoma recurrence after ablation. World J Gastroenterol 2015;21:10418-26.

154. Kim SH, Lee WJ, Lim HK, Lim JH. Prediction of viable tumor in hepatocellular carcinoma treated with transcatheter arterial chemoembolization: usefulness of attenuation value measurement at quadruple-phase helical computed tomography. J Comput Assist Tomogr 2007;31:198-203.

155. Kokabi N, Ludwig JM, Camacho JC, Xing M, Mittal PK, et al. Baseline and early MR apparent diffusion coefficient quantification as a predictor of response of unresectable hepatocellular carcinoma to doxorubicin drug-eluting bead chemoembolization. J Vasc Interv Radiol 2015;26:1777-86.

156. Kim HC, Kim AY, Han JK, Chung JW, Lee JY, et al. Hepatic arterial and portal venous phase helical CT in patients treated with transcatheter arterial chemoembolization for hepatocellular carcinoma: added value of unenhanced images. Radiology 2002;225:773-80.

157. Ebied OM, Federle MP, Carr BI, Pealer KM, Li W, et al. Evaluation of responses to chemoembolization in patients with unresectable hepatocellular carcinoma. Cancer 2003;97:1042-50.

158. Park HJ, Kim JH, Choi SY, Lee ES, Park SJ, et al. Prediction of therapeutic response of hepatocellular carcinoma to transcatheter arterial chemoembolization based on pretherapeutic dynamic CT and textural findings. Am J Roentgenol 2017;209:W211-20.

159. Maesaka K, Sakamori R, Yamada R, Tahata Y, Urabe A, et al. Hypovascular hepatic nodules as a predictive factor for transcatheter arterial chemoembolization refractoriness in hepatocellular carcinoma. Hepatol Res 2020;50:365-73.

160. Choi SJ, Kim J, Seo J, Kim HS, Lee JM, et al. Parametric response mapping of dynamic CT as an imaging biomarker to distinguish viability of hepatocellular carcinoma treated with transcatheter arterial chemoembolization. Abdom Imaging 2014;39:518-25.

161. Huppertz A, Haralda S, Kraus A, Zech CJ, Scheidler J, et al. Enhancement of focal liver lesions at gadoxetic acid-enhanced MR imaging: correlation with histopathologic findings and spiral CT-initial observations. Radiology 2005;234:468-78.

162. Ishimaru H, Nakashima K, Sakugawa T, Sakamoto A, Matsuoka Y, et al. Local recurrence after chemoembolization of hepatocellular carcinoma: uptake of gadoxetic acid as a new prognostic factor. Am J Roentgenol 2014;202:744-51.

163. Ou HY, Cheng YF, Chuang YH, Hsu HW, Chen CL, et al. Quantification of functional MR predicts early response in post-doxorubicin 
drug-eluting beads chemoembolization for hepatocellular carcinoma. Dig Dis Sci 2019; Epub ahead of print. doi: 10.1007/s10620-01905951-6.

164. Kobayashi T, Kawai H, Nakano O, Abe S, Kamimura H, et al. Rapidly declining skeletal muscle mass predicts poor prognosis of hepatocellular carcinoma treated with transcatheter intra-arterial therapies. BMC Cancer 2018;18:756.

165. Eggert T, Greten TF. Current standard and future perspectives in non-surgical therapy for hepatocellular carcinoma. Digestion 2017;96:1-4.

166. Minami Y. Radiofrequency ablation of hepatocellular carcinoma: current status. World J Radiol 2010;2:417.

167. Lau WY, Lai ECH. The current role of radiofrequency ablation in the management of hepatocellular carcinoma: a systematic review. Ann Surg 2009;249:20-5.

168. Na BG, Kim JM, Oh DK, Lee KW, Kang TW, et al. Clinical outcomes of laparoscopic radiofrequency ablation of single primary or recurrent hepatocellular carcinoma $(\leq 3 \mathrm{~cm})$. Ann Surg Treat Res 2017;92:355-60.

169. Lencioni R, Cioni D, Crocetti L, Franchini C, Della Pina C, et al. Early-stage hepatocellular carcinoma in patients with cirrhosis: Longterm results of percutaneous image-guided radiofrequency ablation. Radiology 2005;234:961-7.

170. Nault JC, Sutter O, Nahon P, Ganne-Carrié N, Séror O. Percutaneous treatment of hepatocellular carcinoma: State of the art and innovations. J Hepatol 2018;68:783-97.

171. Toshimori J, Nouso K, Nakamura S, Wada N, Morimoto Y, et al. Local recurrence and complications after percutaneous radiofrequency ablation of hepatocellular carcinoma: a retrospective cohort study focused on tumor location. Acta Med Okayama 2015;69:205-12.

172. Tiong L, Maddern GJ. Systematic review and meta-analysis of survival and disease recurrence after radiofrequency ablation for hepatocellular carcinoma. Br J Surg 2011;98:1210-24.

173. Sparchez Z, Mocan T, Radu P, Mocan LP, Sparchez M, et al. Prognostic factors after percutaneous radiofrequency ablation in the treatment of hepatocellular carcinoma. Impact of incomplete ablation on recurrence and overall survival rates. J Gastrointest Liver Dis 2018;27:399-407.

174. Wu CY, Chen YJ, Ho HJ, Hsu YC, Kuo KN, et al. Association between nucleoside analogues and risk of hepatitis B virus-related hepatocellular carcinoma recurrence following liver resection. JAMA 2012;308:1906-13.

175. N'Kontchou G, Mahamoudi A, Aout M, Ganne-Carrié N, Grando V, et al. Radiofrequency ablation of hepatocellular carcinoma: longterm results and prognostic factors in 235 western patients with cirrhosis. Hepatology 2009;50:1475-83.

176. European Association for Study of Liver; Asociacion Latinoamericana para el Estudio del Higado. EASL-ALEH Clinical Practice Guidelines: non-invasive tests for evaluation of liver disease severity and prognosis. J Hepatol 2015;63:237-64.

177. Rekik S, Allaire M, Mumana A, Guyot E, Nkontchou G, et al. Transient elastography predicts survival after radiofrequency ablation of hepatocellular carcinoma developing on cirrhosis. J Gastroenterol Hepatol 2020;35:142-50.

178. Llovet JM, Real MI, Montaña X, Planas R, Coll S, et al. Arterial embolisation or chemoembolisation versus symptomatic treatment in patients with unresectable hepatocellular carcinoma: a randomised controlled trial. Lancet 2002;359:1734-9.

179. Kong J, Li S, Fan H, Zhang L, Zhao H, et al. Transarterial chemoembolization extends long-term survival in patients with unresectable hepatocellular carcinoma. Medicine (Baltimore) 2018;97:e11872.

180. Liapi E, Georgiades CC, Hong K, Geschwind JFH. Transcatheter arterial chemoembolization: current technique and future promise. Tech Vasc Interv Radiol 2007;10:2-11.

181. Sieghart W, Hucke F, Peck-Radosavljevic M. Transarterial chemoembolization: modalities, indication, and patient selection. J Hepatol 2015;62:1187-95.

182. Dhanasekaran R, Kooby DA, Staley CA, Kauh JS, Khanna V, et al. Comparison of conventional transarterial chemoembolization (TACE) and chemoembolization with doxorubicin Drug Eluting Beads (DEB) for unresectable Hepatocelluar Carcinoma (HCC). J Surg Oncol 2010;101:476-80.

183. Poon RTP, Tso WK, Pang RWC, Ng KKC, Woo R, et al. A phase I/II trial of chemoembolization for hepatocellular carcinoma using a novel intra-arterial drug-eluting bead. Clin Gastroenterol Hepatol 2007;5:1100-8.

184. Yamaguchi R, Yano H, Iemura A, Ogasawara S, Haramaki M, et al. Expression of vascular endothelial growth factor in human hepatocellular carcinoma. Hepatology 1998;28:68-77.

185. Ogasawara S, Yano H, Iemura A, Hisaka T, Kojiro M. Expressions of basic fibroblast growth factor and its receptors and their relationship to proliferation of human hepatocellular carcinoma cell lines. Hepatology 1996;24:198-205.

186. Zhu CB, Wang C, Chen LL, Ma GL, Zhang SC, et al. Serum YKL-40 independently predicts outcome after transcatheter arterial chemoembolization of hepatocellular carcinoma. PLoS One 2012;7:e44648.

187. Casadei Gardini A, Conti F, Foschi FG, Brillanti S, Andreone P, et al. Imbalance of neutrophils and lymphocyte counts can be predictive of hepatocellular carcinoma occurrence in hepatitis C-related cirrhosis treated with direct-acting antivirals. Gastroenterology 2018;154:2281-2.

188. Casadei Gardini A, Foschi FG, Conti F, Petracci E, Vukotic R, et al. Immune inflammation indicators and ALBI score to predict liver cancer in HCV-patients treated with direct-acting antivirals. Dig Liver Dis 2019;51:681-8.

189. Wang B, Li F, Cheng L, Zhan Y, Wu B, et al. The pretreatment platelet count is an independent predictor of tumor progression in patients undergoing transcatheter arterial chemoembolization with hepatitis B virus-related hepatocellular carcinoma. Futur Oncol 2019;15:82739.

190. Wu YQ, Fan WZ, Xue M, Guo J, Wei JL, et al. 25-OH-vitamin D deficiency identifies poor tumor response in hepatocellular carcinoma treated with transarterial chemoembolization. Clin Transl Oncol 2020;22:70-80.

191. Zhang JB, Chen Y, Zhang B, Xie X, Zhang L, et al. Prognostic significance of serum gamma-glutamyl transferase in patients with 
intermediate hepatocellular carcinoma treated with transcatheter arterial chemoembolization. Eur J Gastroenterol Hepatol 2011;23:78793.

192. Shen H, Zheng S, Chen R, Jin X, Xu X, et al. Prognostic significance of serum procalcitonin in patients with unresectable hepatocellular carcinoma treated with transcatheter arterial chemoembolization. Medicine (Baltimore) 2017;96:e7438.

193. Liu PH, Hsu CY, Hsia CY, Lee YH, Su CW, et al. Prognosis of hepatocellular carcinoma: assessment of eleven staging systems. J Hepatol 2016;64:601-8.

194. Biselli M, Andreone P, Gramenzi A, Trevisani F, Cursaro C, et al. Transcatheter arterial chemoembolization therapy for patients with hepatocellular carcinoma: a case-controlled study. Clin Gastroenterol Hepatol 2005;3:918-25.

195. Brown DB, Fundakowski CE, Lisker-Melman M, Crippin JS, Pilgram TK, et al. Comparison of MELD and Child-Pugh scores to predict survival after chemoembolization for hepatocellular carcinoma. J Vasc Interv Radiol 2004;15:1209-18.

196. Testa R, Testa E, Giannini E, Botta F, Malfatti F, et al. Trans-catheter arterial chemoembolisation for hepatocellular carcinoma in patients with viral cirrhosis: Role of combined staging systems, Cancer Liver Italian Program (CLIP) and Model for End-stage Liver Disease (MELD), in predicting outcome after treatm. Aliment Pharmacol Ther 2003;17:1563-9.

197. Xu L, Peng ZW, Chen MS, Shi M, Zhang YJ, et al. Prognostic nomogram for patients with unresectable hepatocellular carcinoma after transcatheter arterial chemoembolization. J Hepatol 2015;63:122-30.

198. Sasaki R, Taura N, Miyazoe Y, Yamamichi S, Nakashiki S, et al. Ketone bodies as a predictor of prognosis of hepatocellular carcinoma after transcatheter arterial chemoembolization. Nutrition 2018;50:97-103.

199. Yu X, Ge N, Guo X, Shen S, Liang J, et al. Genetic variants in the EPCAM gene is associated with the prognosis of transarterial chemoembolization treated hepatocellular carcinoma with portal vein tumor thrombus. PLoS One 2014;9:e93416.

200. Hu W, Huang S, Dong L, Yu C, Li C, et al. MDR1 gene polymorphism correlated with pathological characteristics and prognosis in patients with primary hepatocellular carcinoma receiving interventional therapy. Anticancer Drugs 2019;30:233-40.

201. Zhang H, Guo X, Dai J, Wu Y, Ge N, et al. Genetic variations in IDH gene as prognosis predictors in TACE-treated hepatocellular carcinoma patients. Med Oncol 2014;31:1-8.

202. Liang KH, Lin CL, Chen SF, Chiu CW, Yang PC, et al. GALNT14 genotype effectively predicts the therapeutic response in unresectable hepatocellular carcinoma treated with transcatheter arterial chemoembolization. Pharmacogenomics 2016;17:353-66.

203. Wang G, Bi C. Correlations of pri-Let-7 gene polymorphisms with the recurrence and metastasis of primary liver cancer after transcatheter arterial chemoembolization. Pathol Res Pract 2018;214:667-72.

204. Fako V, Martin SP, Pomyen Y, Budhu A, Chaisaingmongkol J, et al. Gene signature predictive of hepatocellular carcinoma patient response to transarterial chemoembolization. Int J Biol Sci 2019;15:2654-63.

205. Spârchez Z, Mocan T, Radu P, Anton O, Comsa M, et al. Contrast enhanced ultrasonography in assessing the treatment response to transarterial chemoembolization in patients with hepatocellular carcinoma. Med Ultrason 2016;18:96-102.

206. Sung SA, Kim MJ, Joon SL, Hong HS, Yong EC, et al. Added value of gadoxetic acid-enhanced hepatobiliary phase MR imaging in the diagnosis of hepatocellular carcinoma. Radiology 2010;255:459-66.

207. Hwang J, Kim SH, Kim YS, Lee MW, Woo JY, et al. Gadoxetic acid-enhanced MRI versus multiphase multidetector row computed tomography for evaluating the viable tumor of hepatocellular carcinomas treated with image-guided tumor therapy. J Magn Reson Imaging 2010;32:629-38.

208. Tacher V, Lin M, Duran R, Yarmohammadi H, Lee H, et al. Comparison of existing response criteria in patients with hepatocellular carcinoma treated with transarterial chemoembolization using a 3D quantitative approach. Radiology 2016;278:275-84. 